\title{
How some demographic factors affects postpartum haemorrhage prevention in Maiduguri, Nigeria*
}

\author{
Sadiq G. Uthman ${ }^{1 \#}$, Mairiga A. Garba ${ }^{2}$, Ado G. Danazumi ${ }^{2}$, Mairo U. Mandara ${ }^{3,4}$, \\ Nwaosu H. Sylvester ${ }^{5}$ \\ ${ }^{1}$ Department of Ethno-Pharmacy and Drug Development, Faculty of Pharmacy, University of Maiduguri, Maiduguri, Nigeria \\ ${ }^{2}$ Department of Obstetrics and Gynaecology, University of Maiduguri, Maiduguri, Nigeria \\ ${ }^{3}$ Department of Pharmacology and Therapeutics, Faculty of Pharmaceutical Services, Ahmadu Bello University, Zaria, Nigeria \\ ${ }^{4}$ Population and Reproductive Health Research Initiative of Department of Obstetrics and Gynaecology, Ahmadu Bello University \\ Teaching Hopspital, Zaria, Nigeria. \\ ${ }^{5}$ Department of Maths and Statistics, Faculty of Science, University of Maiduguri, Maiduguri, Nigeria \\ Email: "garbaus2000@yahoo.co.uk
}

Received 29 September 2012; revised 30 October 2012; accepted 8 November 2012

\begin{abstract}
Aim: The following work studied how tribal affiliation, educational level and occupation of some women that had PPH in Maiduguri metropolis between September 2007 and March 2009 relate with PPH occurrence. The study was aimed at identifying possible risk factors and also to compare the relative prevention efficacies of oxytocin or misoprostol within the matrix of these factors. Method: A total of 1800 pregnant women who have received either oxytocin injection or oral misoprostol in third stage of labour as a prophylaxis of postpartum haemorrhage, were enrolled within three health care facilities in Maiduguri, Nigeria. Each patient was observed at parturition and for $24 \mathrm{~h}$ after, during which blood lost was estimated to the nearest millilitres. Demographic characteristics were recorded in a structured proforma. The relationship of the occurrence of PPH (occurrence of blood loss $>500 \mathrm{ml}$ ) and mean blood loss (MBL) was studied with respect to the prophylactic medication used and some demographic factors. Results: The incidence of PPH was higher in Igbo, and some "minority" tribes of Borno state (Babur, Bura, Mafa). The tribes that constituted the majority of the study population (Kanuri, and Hausa) exhibited low incidences of PPH. Significant relationships were demonstrated between PPH and educational levels and occupations of participants. Conclussions: It was concluded that PPH occurrence is related to tribal affiliation, educational level and occupation, and the relative efficacies of oxytocin and misoprostol varies between the tribal groups.
\end{abstract}

\footnotetext{
"Conflict of interest: The authors do not have any conflict of interest.

\#Corresponding author.
}

Keywords: Postpartum Haemorrhage; Tribal Affiliation; Risk-Factors; Maiduguri; Oxytocin; Misoprostol

\section{INTRODUCTION}

Globally, over half a million women die annually from causes related to pregnancy and childbirth [1]. The single most common cause of maternal mortality is obstetric haemorrhage, generally occurring postpartum and accounting for $25 \%-33 \%$ of all maternal deaths. The rate of death due to PPH varies widely in the world. The proportions range from less than $10 \%$ in developed countries to nearly $60 \%$ in some third world countries [2]. In Borno State, haemorrhage is the second most important cause of maternal death after hypertension [3]. PPH is hence seen as a major cause of maternal mortality, particularly in the developing world, and of maternal morbidity in both the developed and the developing world [4].

Factors known to put a woman at higher risk for PPH include previous history of PPH; prolonged, augmented preapitate labour, pre-eclampsia; operative delivery; chorioamnionitis; or an overdistended uterus due to macrosomia, twins, or hydramnios [5]. However, PPH generally occurs without warning and the majority of women affected present with no known risk factors $[5,6]$. The aim of this work is to study how some demographic factors relates with PPH in women in Maiduguri and to determine the the relative effectiveness of prevention of $\mathrm{PPH}$ by intravenous oxytocin or oral misoprostol within the matrix of varying maternal factors. The absence of adequate data in the literature of reports (studies or clinical experience) regarding how maternal factors affects PPH in North Eastern Nigeria, justifies the rationale for this study and establishes its significance. 


\section{METHODS}

The study was a prospective, comparative and multicentred one, which was started in September 2007 and completed in March 2009. It was conducted in three health institutions in Maiduguri metropolitan area of Borno state. These were; the University of Maiduguri Teaching Hospital (UMTH), the Maiduguri Specialist Hospital, and Yerwa Maternal and Child Health Care Centre. Women that had uncomplicated vaginal delivery and were administered with a prophylactic dose of either oxytocin injection $(10 \mathrm{IU})$ or oral misoprostol $(3 \times 200 \mu \mathrm{g})$ as permitted by the ethics of practice in the various centre were enrolled for the study. Exclusion criteria included known allergy to either of the drugs, operative delivery, history of co-morbid conditions like diabetes, mal-presentation, anaemia, antepartum haemorrhage, multiple pregnancy, and grandmultiparity (greater than six births). The study was completed with a total sample size of 1865 orally consenting (some written) enrolees. However, 46 of the administered questionnaire were invalidated leaving a total of 1819 valid questionnaires (912 for oxytocin and 907 for misoprostol). The data was further reduced to 1800 through a process of computer randomization so as to have equal study population in the two medication groups: oxytocin group (900 subjects) and misoprostol group (900 subjects). Each patient was observed for a period of $24 \mathrm{~h}$ for blood loss which was quantified using calibrated kidney dishes of various sizes $(100-1500 \mathrm{ml})$ and measured to the nearest millilitres. Clinical measures were administered by a clinician based on patients' needs.

The bio-data of the consenting enrolees were obtained from their clinical folders. The primary outcome measure was total blood loss over $24 \mathrm{~h}$ in $\mathrm{ml}$ and those $\geq 500 \mathrm{ml}$ were classified as PPH (Yes), whereas $<500 \mathrm{ml}$ were PPH (No). Ethical approval for the conduct of the research was given by the Research and Ethical Committee of UMTH through letter referenced as ADM/TH/75/ Vol.II and dated 10th September 2007. The principles of Good Clinical Practice as revised by the Imperial College London, were adhered to in the conduct of this research work. The minimum sample size for the study was calculated using the Taylors' formula at $95 \%$ confidence taking prevalence of $\mathrm{PPH}$ to be $50 \%$. This gave a minimal required sample size of 385 . However, 1800 patients (900 in oxytocin and 900 in misoprostol medication groups) were enrolled for the study in order to take care attrition and to increase power. The statistical software SPSS version 16 (SPSS Chi, Ill USA) was used for statistical analysis. Mean values were compared using student $t$ test for continuous variables and chi square $\chi^{2}$ test for categorical variables. The level of significance was set at $\mathrm{p}<0.05$ and at $\mathrm{p}<0.001$.

\section{RESULTS}

\subsection{The Influence of Tribal Affiliation on PPH and MBL}

Table 1 shows statistically significant differences in occurrence of PPH $(p<0.001)$ and in MBL $(p<0.05)$ between the various tribal groupings of the study population. A uniform trend both in occurrences of PPH and values of MBL within the tribes was observed as the lowest PPH prevalence $(0.8 \%)$ happened to be in Fulani tribe which was also the tribe with the lowest MBL $(302.50 \mathrm{ml} \pm 2.202)$. The Mafa tribe had the highest occurrence of PPH (46.9\%) and also the highest measure of MBL (585.00 $\mathrm{ml} \pm 47.487)$.

\subsection{The Influence of Tribal Affiliation on the Effectiveness of the Medications}

Table 2 shows the relative efficacy of Oxytocin injection and oral misoprostol in the various tribal groups. The percentage prevention of PPH by oxytocin injection was higher than that of the misoprostol tablets in the major tribal groups of Kanuri $(91.4 \%$ versus $89.0 \%$ ), Hausa $(88.2 \%$ versus $86.7 \%)$ and Babur $(83.9 \%$ versus $70.8 \%)$. On the other hand, the percentage prevention by misoprostol tablet is higher in Shuwa (100\% versus $61.3 \%)$ and Fulani (100\% versus $96.9 \%)$.

Table 1. Relative risk of post partum haemorrhage and a measure of mean blood loss among tribes of enrolees.

\begin{tabular}{ccccc}
\hline \multirow{2}{*}{ Tribe } & \multicolumn{3}{c}{$\begin{array}{c}\text { Occurrence of Post Partum } \\
\text { Haemorrhage Number }(\%)\end{array}$} & $\begin{array}{c}\text { Mean Blood } \\
\text { Loss (MBL) } \\
(\mathrm{ml})\end{array}$ \\
\cline { 2 - 4 } & No & Yes & Total & \\
\hline Mafa & $17(53.1)$ & $15(46.9)$ & $32(100)$ & $585.00 \pm 47.49$ \\
Others & $96(83.5)$ & $19(16.5)$ & $115(100)$ & $444.29 \pm 22.02$ \\
Margi & $95(84.8)$ & $17(15.2)$ & $112(100)$ & $401.43 \pm 19.65$ \\
Hausa & $225(87.5)$ & $32(12.5)$ & $257(100)$ & $388.13 \pm 12.85$ \\
Shuwa & $144(82.3)$ & $31(18.1)$ & $175(100)$ & $367.27 \pm 11.40$ \\
Babur & $128(80.0)$ & $32(20.0)$ & $160(100)$ & $345.00 \pm 9.40$ \\
Igbo & $33(68.8)$ & $15(31.3)$ & $48(100)$ & $333.33 \pm 20.87$ \\
Kanuri & $563(89.8)$ & $64(10.2)$ & $627(100)$ & $330.77 \pm 4.10^{\mathrm{f}}$ \\
Bura & $18(56.3)$ & $14(43.7)$ & $32(100)$ & $310.00 \pm 1.79^{\mathrm{g}}$ \\
Fulani & $128(99.2)$ & $1(0.8)$ & $129(100)$ & $302.50 \pm 2.20$ \\
\hline
\end{tabular}

$\mathrm{P}_{1}<0.001 ; \mathrm{p}$ value for occurrence of PPH in the various tribal groups by chi square statistics; $\mathrm{P}_{2}<0.05 ; \mathrm{p}$ value for differences in MBL between the various tribal groups by ANOVA statistics; Means with non similar superscript implies statistically significant difference (Tamhane's T2 post hoc multiple analysis); There was a strong positive correlation (0.617) that was statistically significant $(\mathrm{p}<0.001)$ between maternal tribal affiliations and MBL (with parity, number of deliveries, maternal age and resting periods being controlled variables). 
Table 2. Relative risk of post partum haemorrhage and a measure of mean blood loss among tribes of enrolees in the two medication groups of intravenous oxytocin injection and oral misoprostol tablet.

\begin{tabular}{cccccc}
\hline \multirow{2}{*}{ Tribe } & Medication Group & \multicolumn{2}{c}{ Occurrence of Post Partum Haemorrhage (PPH) Number (\%) } & Mean Blood Loss \\
\cline { 3 - 5 } & & No & Yes & Total & (MBL) (ml) \\
\cline { 3 - 5 } Hausa & Oxytocin & $127(88.2)$ & $17(11.8)$ & $144(100)$ & $381.11 \pm 16.92$ \\
& Misoprostol & $98(86.7)$ & $15(13.3)$ & $113(100)$ & $397.14 \pm 19.77$ \\
Igbo & Oxytocin & $33(68.8)$ & $15(31.3)$ & $48(100)$ & $333.33 \pm 20.87$ \\
& Misoprostol & Nil & Nil & Nil & \\
Kanuri & Oxytocin & $191(91.4)$ & $18(8.6)$ & $209(100)$ & $343.85 \pm 5.65$ \\
& Misoprostol & $372(89.0)$ & $46(11.0)$ & $418(100)$ & $324.23 \pm 5.43$ \\
Shuwa & Oxytocin & $49(61.3)$ & $31(38.7)$ & $80(100)$ & $460.00 \pm 20.82$ \\
& Misoprostol & $95(100.0)$ & $0(0.0)$ & $95(100)$ & $290.00 \pm 1.02$ \\
Fulani & Oxytocin & $31(96.9)$ & $1(3.1)$ & $32(100)$ & $335.00 \pm 2.69$ \\
& Misoprostol & $97(100.0)$ & $0(0.0)$ & $97(100)$ & $291.67 \pm 1.72$ \\
Babur & Oxytocin & $94(83.9)$ & $18(16.1)$ & $112(100)$ & $344.29 \pm 10.12$ \\
& Misoprostol & $34(70.8)$ & $14(29.2)$ & $48(100)$ & $346.67 \pm 20.76$ \\
Total & Oxytocin & 525 & 100 & 625 & \\
& Misoprostol & 696 & 75 & 771 & \\
\hline
\end{tabular}

$\mathrm{p}_{\text {oxy: } 1}<0.001 ; \mathrm{p}$ value in oxytocin medication group by chi square statistics; $\mathrm{p}_{\text {miso; } 1}<0.001 ; \mathrm{p}$ value in misoprostol medication group by chi square statistics; $p_{\text {oxy; } 2}<0.001 ; \mathrm{p}$ value for MBL between groups (in oxytocin medication group) by ANOVA statistics; $\mathrm{p}_{\text {miso; } 2}<0.001 \mathrm{p}$ value for MBL between groups (in misoprostol medication group) by ANOVA statistics.

\subsection{The Influence of Educational Level on the Occurrence of PPH and MBL}

Table 3 shows that there was a significant $(p<0.001)$ increase in the occurrence of PPH as the educational level of the participant increases from primary $(0.0 \%)$, to secondary $(12.4 \%)$ and to tertiary $(17.1 \%)$ educational level. This trend was not supported by MBL. There was a weak negative correlation $(-0.113)$ that is not statistically significant $(\mathrm{p}>0.05)$ between MBL and educational background of enrolees (with parity, number of deliveries, maternal age, tribal affiliations and resting periods being controlled variables).

\subsection{The Influence of Occupation on PPH and MBL}

Table 4 shows that there was a significant change in the occurrence of PPH $\left(\mathrm{P}_{1}<0.001\right)$ and in the values of MBL $\left(\mathrm{P}_{1}<0.001_{2}\right)$ with respect to occupation of participants. The fewest occurrences were among students $(0.0 \%)$ which also exhibited the lowest MBL (265.00 \pm $24.191 \mathrm{ml}$ ). The highest occurrence of PPH was among the civil servants $(27.7 \%)$ and this was supported by the highest MBL of $387.14 \pm 18.680 \mathrm{ml}$. There was a weak positive correlation $(0.001)$ that is not statistically significant $(p>0.05)$ between MBL and occupation of enrolees (with parity, number of deliveries, educational background, type of medication, maternal age, tribal affiliations and resting periods being controlled variables).
Table 3. Relative risk of postpartum haemorrhage and a measure of mean blood loss among categories of educational level of enrolees.

\begin{tabular}{|c|c|c|c|c|}
\hline \multirow{2}{*}{$\begin{array}{l}\text { Educational } \\
\text { Background }\end{array}$} & \multicolumn{3}{|c|}{$\begin{array}{c}\text { Occurrence of Post Partum } \\
\text { Haemorrhage (PPH) Number (\%) }\end{array}$} & \multirow{2}{*}{$\begin{array}{l}\text { Mean Blood } \\
\text { Loss (MBL) } \\
\quad(\mathrm{ml})\end{array}$} \\
\hline & No & Yes & Total & \\
\hline Primary & $49(100.0)$ & $0(0.0)$ & $49(100)$ & $520.00 \pm 28.91^{\mathrm{a}}$ \\
\hline Tertiary & $160(82.9)$ & $33(17.1)$ & $193(100)$ & $372.50 \pm 12.33^{b}$ \\
\hline Qur'anic & $223(81.7)$ & $50(18.3)$ & $273(100)$ & $361.18 \pm 8.69^{\mathrm{b}, \mathrm{c}}$ \\
\hline None & $803(89.3)$ & $96(10.7)$ & $899(100)$ & $351.07 \pm 5.23^{\mathrm{c}}$ \\
\hline Secondary & $127(87.6)$ & $18(12.4)$ & $145(100)$ & $308.89 \pm 7.44^{\mathrm{d}}$ \\
\hline Total & 1362 & 197 & 1559 & \\
\hline
\end{tabular}

$\mathrm{P}_{1}<0.001 ; \mathrm{p}$ value for occurrence of $\mathrm{PPH}$ in the various birth interval groups by chi square statistics; $\mathrm{P}_{2}<0.001$; $\mathrm{p}$ value for $\mathrm{MBL}$ between the groups by ANOVA statistics; Means with non similar superscript implies statistically significant difference, where as those with similar superscript implies no significant difference between them (Tamhane's T2 post hoc multiple analysis); There was a weak negative correlation $(-0.113)$ that is not statistically significant $(\mathrm{p}>0.05)$ between MBL and educational background of enrolees (with parity, number of deliveries, maternal age, tribal affiliations and resting periods being controlled variables).

\section{DISCUSSION}

\subsection{Influence of Tribal Affiliation}

The significant variation in occurrence of PPH between the tribal groups suggests that tribal affiliation is a risk factor for PPH. PPH was found to be affiliated with His- 
Table 4. Relative risk of postpartum haemorrhage and a measure of mean blood loss among various occupation of enrolees.

\begin{tabular}{|c|c|c|c|c|}
\hline \multirow{2}{*}{ Occupation } & \multicolumn{3}{|c|}{$\begin{array}{c}\text { Occurrence of Post Partum } \\
\text { Haemorrhage (PPH) Number (\%) }\end{array}$} & \multirow{2}{*}{$\begin{array}{l}\text { Mean Blood } \\
\text { Loss (MBL) } \\
\quad(\mathrm{ml})\end{array}$} \\
\hline & No & Yes & Total & \\
\hline Civil Servants & $80(72.3)$ & $31(27.7)$ & $111(100)$ & $387.14 \pm 18.68^{\mathrm{a}}$ \\
\hline Self Employed & $16(100.0)$ & $0(0.0)$ & $16(100)$ & $350.00 \pm 0.00^{\mathrm{a}, \mathrm{b}}$ \\
\hline House Wives & 1398 (87.0) & $209(13.0)$ & $1607(100)$ & $338.70 \pm 3.79^{b}$ \\
\hline Students & $33(100.0)$ & $0(0.0)$ & $33(100)$ & $265.00 \pm 24.19^{c}$ \\
\hline Total & 1527 & 240 & 1767 & \\
\hline
\end{tabular}

Key: $\mathrm{P}_{1}<0.001 ; \mathrm{p}$ value for occurrence of PPH in the various birth interval groups by Chi square statistics; $\mathrm{P}_{2}<0.05 ; \mathrm{p}$ value for $\mathrm{MBL}$ between the birth interval groups by ANOVA statistics; Means with non similar superscript implies statistically significant difference, where as those with similar superscript implies no significant difference between them (Tamhane's T2 post hoc multiple analysis); There was a weak positive correlation (0.001) that is not statistically significant $(\mathrm{p}>0.05)$ between MBL and occupation of enrolees (with parity, number of deliveries, educational background, type of medication, maternal age, tribal affiliations and resting periods being controlled variables).

panics and Asian races [7-9]. Tribal groupings usually varies with cultural norms and customs. These, as well as a lack of education and decision-making power conspire to limit access to an ideal environment for pregnancy and childbirth [10]. Furthermore, reliance on rituals, prayer or magic and fear of medical personnel or technologywhich varies amongst the tribal groups-may delay or prevent adequate health care services [11-13].

In Nigeria, $17 \%$ of women brought to the hospital for complications during childbirth stated they avoided early care at the onset of labour for fear of forced tubal ligation [14]. The disconnect between cultural beliefs and clinical practice results in strong barriers to improving maternal health [15].

\subsection{Influence of the Degree of Educational Level}

The significant increase in the occurrence of PPH with respect to inrease in educational level suggests a linear relationship. In line with this, Drakum (1982) reported that in extremely remote or primitive regions, cultural beliefs combined with a lack of education often dictate a number of practices, including restrictive diet and activity during pregnancy [12]. These combine to modulate pregnancy outcome.

\subsection{Influence of Occupation Type}

The highest occurrence of PPH was among the civil servants and this was supported by the highest MBL of $387.14 \pm 18.680 \mathrm{ml}$. The present outcome does not agree with the notion that lack of education and decisionmaking power conspire to limit access to an ideal environment for safe pregnancy and childbirth. On the other hand, it shows that educational status and occupation of patients constitute and contributes to risk factors for PPH. In line with this philosophy, Graham (1992) and Koblinsky et al. (1992) made the following declaration on improving maternal and child health; "Ultimately what is required is an improvement in socioeconomic conditions, the promotion of female education simultaneously with a broader concept of what constitutes women's health" $[16$, 17].

Efforts have resulted in maternal health moving away from a purely pregnancy-related orientation to reproductive health (WHO, 1992) but this is not far enough [18]. A definition of woman's health as defined by Koblinsky et al., (1992) states "A woman's health is her total wellbeing, not determined solely by biological factors and reproduction, but also the effects of work load, nutrition, stress, war and migration, among others" [17]. If services were delivered based upon a broader concept of women's health and with a view to empowering women to look after their own health needs, there would ultimately be a welcome reduction in the unacceptably high levels of maternal mortality and morbidity currently prevalent in developing countries. The ultimate bonus would be healthier families and all the attending benefits resulting from this desirable achievement.

It was concluded that in the social matrix of multitudes of factors that surround the process of pregnancy and childbirth, tribal affiliation, educational background and occupation plays role in the occurrence of PPH. The contribution of tribal affiliation was significantly higher than the other two factors (Table 5). Oxytocin injection control PPH better than misoprostol among Kanuri, Hausa and Babur trial groups while oral misoprostol was better among Shuwa and Fulani tribes.

\section{ACKNOWLEDGEMENTS}

We are very grateful to the University of Maiduguri, Nigeria, for funding this work (in part) and to Emzor Pharmaceutical Industries Limited Nigeria, for donating misoprostol tablets. We are very grateful to members of the research and ethical committee of the participating health institutions-for giving us not only the permission but their immense advice and suggestions. We are also grateful to the entire staff of

Table 5. Logistic regression of some factors.

\begin{tabular}{ccc}
\hline Variable Factors & Sig & Exp (B) \\
\hline Tribal Affiliation & 0.000 & $1.785^{*}$ \\
Educational Background & 0.001 & 0.241 \\
Occupation & 0.000 & 0.300 \\
\hline
\end{tabular}

Key: $\operatorname{Exp}(\mathrm{B})=$ Exponential coefficient; Note that predicted probability is of membership for yes (i.e. occurrence of $\mathrm{PPH}$ ); The cut value for $\operatorname{Exp}(\mathrm{B})$ is 0.50 . Meaning that factors with $\operatorname{Exp}(\mathrm{B})$ values $>0.50$ contributes significantly to the occurrence of $\mathrm{PPH}$. 
the labour wards in the study sites especially the consultant obstetricians and medical officers. Finally, we humbly give thanks and appreciations to our colleagues at the following three institutions; UMTH Pharmacy department, the Faculty of Pharmacy, University of Maiduguri, and those at the Faculty of Pharmacy ABU Zaria.

\section{DISCLOSURE}

None of the authors has any financial relationship whether directly or indirectly with any company or institution that may have special interest in this work.

\section{REFERENCES}

[1] WHO (2005) World health report 2005-Make every mother and child count. World Health Organization, Geneva.

[2] Abou Zahr, C. (1998) Antepartum and postpartum haemorrhage. Health dimensions of sex and reproduction. MA7 Harvard School of Public Health on behalf of the World Health Organization and the World Bank, Cambridge, 165-189.

[3] Mairiga, A.G., Kawuwa, M.B. and Kyari, O. (2008) A fourteen-year review of maternal mortality at the University of Maiduguri Teaching Hospital, Maiduguri, Nigeria. Nigerian Hospital Practice, 2, 115-118

[4] Cameron, M.J. and Robson, S.C. (2006) Vital statistics: An overview in a text book of post partum haemorrhage. Sapiens Publishing, Dunccow, 2006.

[5] American College of Obstetricians and Gynecologists (2006) ACOG practice bulletin: Clinical management guidelines for obstetrician gynecologists. Obstetrics \& Gynecology, 108, 1039-1047

[6] WHO (2007) Guidelines for the prevention of postpartum haemorrhage. World Health Organization, Geneva.

[7] Combs, C.A., Murphy, E.L. and Laros Jr., R.K. (1991) Factors associated with postpartum hemorrhage in vaginal birth. Obstetrics and Gynaecology, 77, 69-76.
[8] Combs, C.A., Murphy, E.L. and Laros Jr., R.K. (1991) Factors associated with hemorrhage in cesarean deliveries. Obstetrics and Gynaecology, 77, 77-82

[9] Magann, E.F., Evans, S., Chauhan, S.P., Lanneau, G., Fisk, A.D. and Morrison, J.C. (2005) The length of the third stage of labor and the risk of postpartum hemorrhage. Obstetrics and Gynaecology, 105, 290-293. doi:10.1097/01.AOG.0000151993.83276.70

[10] Family Care International and the Safe Motherhood InterAgency Group (1998) Safe motherhood fact sheets.

[11] bij de Vaate, A., Coleman, R., Manneh, H. and Walraven, G. (2002) Knowledge, attitudes and practices of trained traditional birth attendants in the Gambia in the prevention, recognition and management of postpartum haemorrhage. Midwifery, 18, 3-11.

[12] Drakum, E.E. (1982) Cultural influences in birth practices in Papua New Guinea. Australian Nurses Journal, 11, 14-15.

[13] Bates, B. and Turner, A.N. (1985) Imagery and symbolism in the birth practices of traditional cultures. Birth, 12, 29-35. doi:10.1111/j.1523-536X.1985.tb00927.x

[14] Fajemilehin, R.B. (1991) Factors influencing high rate of "born-before-arrival" babies in Nigeria-A case control study in Ogbomosho. International Journal of Nursing Studies, 28, 13-18. doi:10.1016/0020-7489(91)90045-5

[15] Pan American Health Organization (2004) Maternal and child mortality among the indigenous peoples of the Americas. Healing our spirit worldwide: Newsletter for indigenous people.

[16] Graham, W. (1992) Maternal health and the measurement trap. Social Science and Medicine, 35, 961-911. doi:10.1016/0277-9536(92)90236-J

[17] Koblinsky, M., Campbell, O. and Harlow, S. (1992). Mother and more: A broader perspective on women's health. In: Koblinsky, M., Timyan, J. and Gay, J., Eds., The Health of Women: A Global Perspective. Westview Press, Boulder.

[18] WHO (1992) Reproductive health: A key to a brighter future. World Health Organization, Geneva. 